\title{
Orthopnea and fever in an elderly woman
}

\author{
Claudio Tana, ${ }^{1}$ Silvio di Carlo, ${ }^{2}$ Mauro Silingardi, ${ }^{3}$ Maria Adele Giamberardino,${ }^{4}$ Francesco Cipollone,, 5 \\ Tiziana Meschi ${ }^{1}$
}

${ }^{1}$ Internal Medicine and Critical Subacute Care Unit, Medicine Geriatric-Rehabilitation Department, University-Hospital of Parma, Parma; ${ }^{2}$ Geriatrics Clinic, Medicine Department, ASL Pescara, Pescara; ${ }^{3}$ Internal Medicine Unit, Maggiore Hospital of Bologna, AUSL Bologna; ${ }^{4}$ Ce.S.I.-Met; and Geriatrics Clinic, Department of Medicine and Science of Aging, G. D'Annunzio University of Chieti; ${ }^{5}$ Regional Center for the Study of Atherosclerosis, Hypertension and Dyslipidemia, S.S. Annunziata Hospital, ASL Chieti, Italy

\begin{abstract}
Orthopnea is a sensation of shortness of breath, which occurs in recumbent position and is usually improved by standing or sitting. The authors report a case of an 81-year-old woman presented to the Emergency Department with a two-week history of orthopnea, fever and low back pain resistant to analgesics. Radiological findings confirm the presence of a diafragmatic hernia, and clinicians should pay attention to any history of trauma, because their absence in symptomatic adult patients directs towards a congenital cause. A surgical repair should be promptly obtained to avoid further general and respiratory deterioration.
\end{abstract}

\section{Introduction}

Orthopnea is a sensation of shortness of breath, which occurs in recumbent position and is usually improved by standing or sitting. ${ }^{1}$ It is different from paroxysmal nocturnal dyspnea, a breathlessness sensation which occurs in the night and awakes the patient 1-2 $\mathrm{h}$ after sleep. ${ }^{2}$ Other different forms of breathlessness are trepopnea, a form of dyspnea occurring in one lateral decubitus and platypnea which occurs in the upright position.

Correspondence: Claudio Tana, Internal Medicine and Critical Subacute Care Unit, Medicine Geriatric-Rehabilitation Department, University-Hospital of Parma, Strada Abbeveratoia 2, 43100 Parma, Italy.

Tel.: +39.0521.702079 - Fax: +39.0521.702383.

E-mail: ctana@ao.pr.it

Key words: Acute respiratory failure; congenital disorders; hernia; diaphragm; computed tomography.

Contributions: CT and SdC contributed equally to the manuscript.

Conflict of interest: the authors declare no potential conflict of interest.

Received for publication: 4 September 2017.

Accepted for publication: 15 September 2017.

This work is licensed under a Creative Commons Attribution NonCommercial 4.0 License (CC BY-NC 4.0).

(C) Copyright C. Tana et al., 2017

Licensee PAGEPress, Italy

Italian Journal of Medicine 2017; 11:399-402

doi:10.4081/itjm.2017.922
Usually, orthopnea presents in advanced heart failure and results from increased pulmonary capillary pressure secondary to central fluid redistribution. Less frequently lung diseases, abdominal obesity, neurological and diaphragm disorders can be associated with this symptom.

\section{Case Report}

An 81-year-old woman presented to the Emergency Department (ED) with a two-week history of orthopnea, fever and low back pain resistant to analgesics. She reported a history of severe constipation treated at home with laxatives. Vital signs were normal except for low peripheral oxygen saturation $(87 \%)$ and fever $\left(38.4^{\circ} \mathrm{C}\right)$. Physical examination revealed reduction in vesicular breath sounds, minimal bibasilar lung crackles and diffuse abdominal tenderness. Laboratory tests showed leukocytosis (white blood cells $16 \times 10^{9} / \mathrm{L}$ ) with neutrophilia, elevation of erythrocyte sedimentation rate, C-reactive protein $(62 \mathrm{~mm} / \mathrm{h}$ and $172 \mathrm{mg} / \mathrm{L}$, respectively), amylase (650 U/L) and lactate dehydrogenase $(955 \mathrm{U} / \mathrm{L})$. Lipase levels were within normal range and blood cultures were negative. Electrocardiogram performed in the ED was normal. Blood gas analysis revealed acute hypercapnic respiratory failure. Chest X-ray showed massive bowel loops herniation into the thoracic cavity (Figure 1A). Contrast-enhanced computed tomography (CECT) confirmed the presence of a large diaphragmatic hernia with massive intestinal and gastric herniation resulting in bowel obstruction, wall ischemia and lung atelectasis from extrinsic compression (Figure 1B and C). There was no history of trauma. Broad-spectrum antibiotics were started, and the patient underwent 
prompt surgical reduction of the hernia and repair of the diaphragmatic defect.

\section{Discussion}

Congenital diaphragmatic hernia $(\mathrm{CDH})$ is a rare disease, occurring in 1 per 3000 live births, in which the diaphragm does not form properly during embryogenesis. ${ }^{3} \mathrm{CDH}$ results in different degrees of aperture of the diaphragm (from small to severe) and patients can be asymptomatic or manifest with acute life-threatening symptoms. ${ }^{3-5}$ The etiology of $\mathrm{CDH}$ is still unknown, but it has been hypothesized a multifactorial etiology in which both genetic and environmental factors play a role. ${ }^{3}$ Recurrent genetic causes are deletions (1q41-42, 4p16, 8p23.1, 8q23.1, 15q26.1, 17.q12), trisomy (chromosome 21, 18, 13, 16, 22) and single mutations in $>20$ different genes resulting in $\mathrm{CDH}$ alone or in combination with other organ abnormalities. Cardiopulmonary, gastrointestinal, musculoskeletal and genitourinary systems can be affected configuring specific clinical syndromes.$^{6-10}$ Environmental factors such as vitamin A deficiency or herbicide exposure (e.g., nitrofen) have also been associated with $\mathrm{CDH} .{ }^{11-14}$

Alcohol use and maternal pregestational diabetes are also significantly associated with $\mathrm{CDH} .{ }^{15}$ The diagnosis is usually achieved with imaging (ultrasound) in the prenatal period, ${ }^{1,2}$ and the evolution of diagnostic techniques has dramatically decreased the number of cases found in post-natal period. ${ }^{16}$
In the elderly, diaphragmatic hernias due to congenital etiology are detected with a frequency of $0.17-$ $6 \%$, being most often associated with acquired causes such as thoraco-abdominal injuries. ${ }^{17}$

Asymptomatic cases are usually missed on a first clinical evaluation, and manifest only with overt signs of complications. ${ }^{17}$ Acute respiratory failure can be the result of severe lung compression from incarcerated bowel loops or stomach. Patients present often with dyspnea. Sometimes they present with orthopnea, which mimics symptoms of heart failure especially if bibasilar crackles are appreciable. ${ }^{18}$ Lung auscultation can reveal also the presence of bowel sounds in one or both chest areas, without any vesicular murmur on examination. ${ }^{17}$ Blood gas analysis can reveal acute type II respiratory failure, but the use of noninvasive positive-pressure ventilation (NPPV) should be used with caution because it can further deteriorate the clinical picture by increasing abdominal pressure and diaphragmatic herniation. ${ }^{19}$

Patients with $\mathrm{CDH}$ can present also with abdominal pain and vomiting secondary to bowel obstruction and volvulus. As in this case, patients can have a chronic history of constipation treated unsuccessfully with laxatives. Fever and tachycardia can dominate the clinical picture in case of bowel strangulation. ${ }^{20}$ In rare cases, gastric volvulus presenting with acute epigastric pain and fever have been described in the literature. These clinical signs should alert clinicians to consult early the surgeon to avoid any therapeutic delay. ${ }^{21,22}$
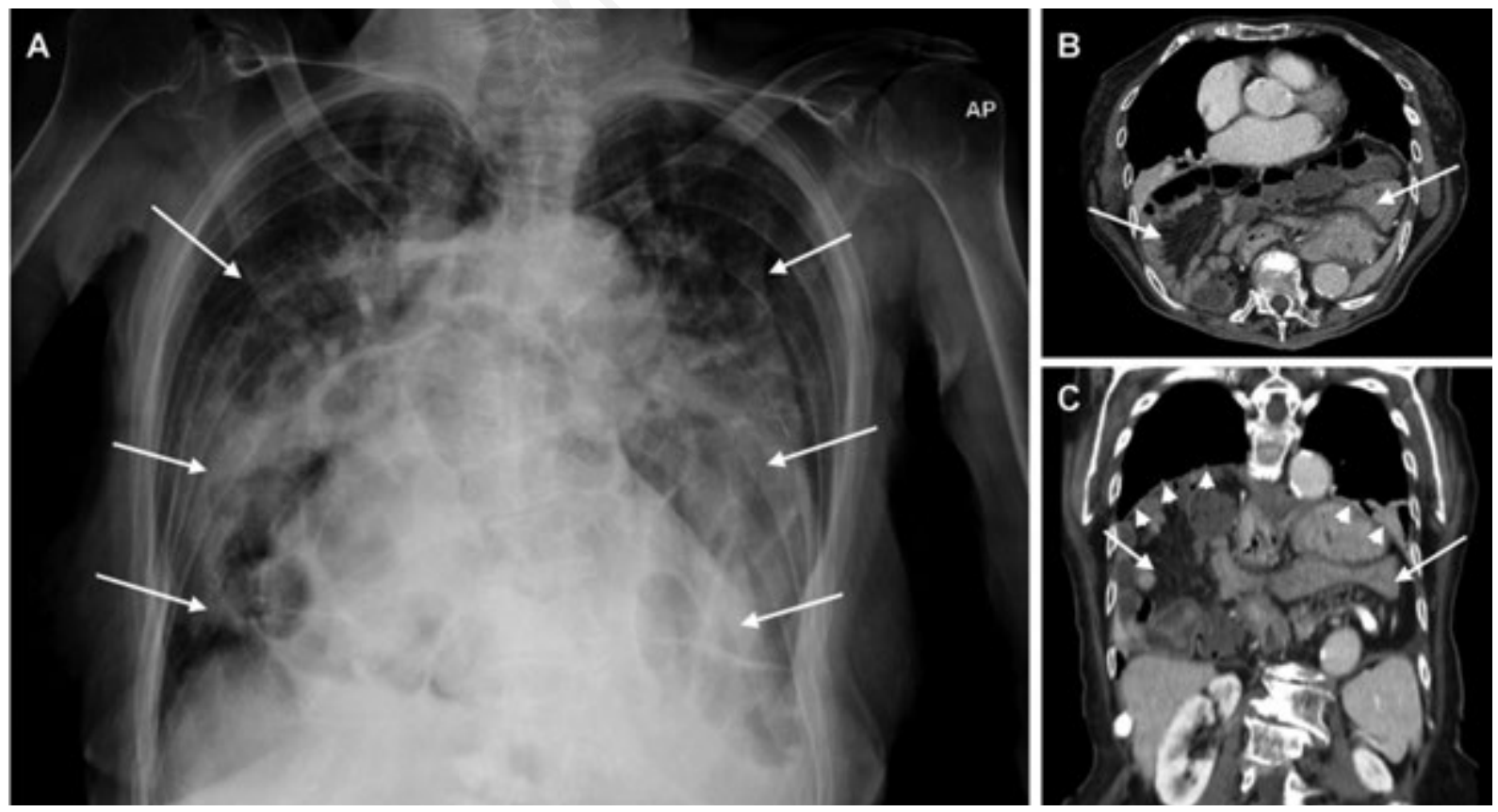

Figure 1. A) Plain chest radiograph showing massive bowel loops herniation into the thoracic cavity (arrows). B and C) Contrast-enhanced computed tomography (axial and coronal view, respectively) of the chest and abdomen revealing also the migration of abdominal organs (arrows) and lung atelectasis (arrowheads) resulting from extrinsic compression. 
The diagnosis can be achieved early with imaging. Chest X-ray can reveal bowel loop and migration of the other abdominal organs into the thoracic cavity, but only CECT can demonstrate and quantify with accuracy the type and severity of the diaphragmatic defect. ${ }^{16,23}$

Some authors have described the utility of magnetic resonance imaging (MRI) in the assessment of $\mathrm{CDH}$. MRI can distinguish the diaphragm discontinuity from eventration and can characterize better the hernia location and size. However, this technique is not feasible in urgent conditions and should be performed only in election in asymptomatic cases or to monitor recurrence after repair of the defect. ${ }^{24}$ Despite its usefulness in the prenatal period, there is lack of evidence regarding the diagnostic contribution of ultrasonography in the adult patients with $\mathrm{CDH} .{ }^{25}$

Surgery is the mainstay of treatment, and should be performed immediately when symptoms or complications arise. ${ }^{3}$ The primary repair of the defect with hernia reduction or the formation of a neo-diaphragm with composite mesh are considered both valid approaches to the $\mathrm{CDH}$. A minimally invasive surgery compared to the traditional open surgical approach is associated with lower post-operative mortality and morbidity. ${ }^{26,27}$ However, some authors have found that patients with a patch have a higher rate of recurrence of $\mathrm{CDH}$ than those who underwent primary repair. ${ }^{28}$ To date, there are not definite conclusions on the best therapeutic approach and there is need of controlled prospective trials aimed at comparing both surgical techniques. In this case, patient was safely treated with primary repair of the diafragmatic defect. Clinical picture rapidly improved after surgery with resolution of symptoms and respiratory failure.

\section{Conclusions: why should a clinician be aware of this?}

In the elderly, ortophnea is a typical symptom of late heart failure and sometimes of advanced pulmonary disorders. Although less frequent, causes such as diafragmatic disorders should be considered. Symptoms and signs such as abdominal pain, bowel obstruction and fever can suggest this alternative diagnosis. Radiological findings confirm the presence of a diafragmatic hernia, and clinicians should pay attention to any history of trauma, because their absence in symptomatic adult patients directs towards a congenital cause. If patients present with acute respiratory failure, NPPV can further aggravate the clinical picture and therefore should be used with caution if a symptomatic $\mathrm{CDH}$ is suspected. A surgical repair should be promptly obtained to avoid further general and respiratory deterioration.

\section{References}

1. Fauci A, Braunwald E, Kasper D, et al. Harrison's principles of internal medicine, 17th ed. New York, NY: McGraw-Hill; 2008.

2. Mukerji V. Dyspnea, orthopnea, and paroxysmal nocturnal dyspnea. In: Walker HK, Hall WD, Hurst JW, eds. Clinical methods: the history, physical, and laboratory examinations, 3rd ed. Boston: Butterworths; 1990. Chapter 11.

3. Harting MT, Lally KP. The congenital diaphragmatic hernia study group registry update. Semin Fetal Neonatal Med 2014;19:370-5.

4. Colvin J, Bower C, Dickinson JE, Sokol J.D. Outcomes of congenital diaphragmatic hernia: a population-based study in Western Australia. Pediatrics 2005;116:e356-63.

5. Naunheim KS. Adult presentation of unusual diaphragmatic hernias. Chest Surg Clin N Am 1998;8:359-69.

6. Wynn J, Yu L, Chung WK.Genetic causes of congenital diaphragmatic hernia. Semin Fetal Neonatal Med 2014; 19:324-30.

7. Esplin ED, Chaib H, Haney M, et al. 46,XY disorders of sex development and congenital diaphragmatic hernia: a case with dysmorphic facies, truncus arteriosus, bifid thymus, gut malrotation, rhizomelia, and adactyly. Am J Med Genet A 2015;167:1360-4.

8. Goumy C, Laffargue F, Eymard-Pierre E, et al. Congenital diaphragmatic hernia may be associated with $17 \mathrm{q} 12$ microdeletion syndrome. Am J Med Genet A 2015; 167A:250-3.

9. Wat MJ, Veenma D, Hogue J, et al. Genomic alterations that contribute to the development of isolated and nonisolated congenital diaphragmatic hernia. J Med Genet 2011;48:299-307.

10. Cunát V, Stranák Z, Pýcha K, et al. Congenital diaphragmatic hernia associated with esophageal atresia, tracheoesophageal fistula, and truncus arteriosus in a premature newborn. Pediatr Surg Int 2005;21:684-6.

11. Chandrasekharan PK, Rawat M, Madappa R, et al. Congenital Diaphragmatic hernia - a review. Matern Health Neonatol Perinatol 2017;3:6.

12. Beurskens LW, Tibboel D, Steegers-Theunissen RP. Role of nutrition, lifestyle factors, and genes in the pathogenesis of congenital diaphragmatic hernia: human and animal studies. Nutr Rev 2009;67:719-30.

13. Anderson D. Incidence of congenital diaphragmatic hernia in the young of rats bred on a diet deficient in Vitamin A. Am J Dis Child 1941;62:888-9.

14. Beurskens LW, Tibboel D, Lindemans J, et al. Retinol status of newborn infants is associated with congenital diaphragmatic hernia. Pediatrics 2010;126:712-20.

15. McAteer JP, Hecht A, De Roos AJ, Goldin AB. Maternal medical and behavioral risk factors for congenital diaphragmatic hernia. J Pediatr Surg 2014;49:34-8.

16. Kharma N. Dysfunction of the diaphragm: imaging as a diagnostic tool. Curr Opin Pulm Med 2013;19:394-8.

17. Testini M, Girardi A, Isernia RM, et al. Emergency surgery due to diaphragmatic hernia: case series and review. World J Emerg Surg 2017;12:23.

18. Wongrakpanich S, Hassidim H, Chaiwatcharayut W, Manatsathit W. A case of giant hiatal hernia in an elderly patient: When stomach, duodenum, colon, and 
pancreas slide into thorax. J Clin Ger Geriatrics 2016;7:112-4.

19. Tone K, Kiryu I, Yoshida M, et al. Morgagni hernia with respiratory failure aggravated by noninvasive positive pressure ventilation: a case report and overview of the literature. Respir Investig 2014;52:203-8.

20. Karanikas ID, Dendrinos SS, Liakakos TD, Koufopoulos IP. Complications of congenital posterolateral diaphragmatic hernia in the adult. Report of two cases and literature review. J Cardiovasc Surg (Torino) 1994;35:555-8.

21. Atef M, Emna T. Bochdalek hernia with gastric volvulus in an adult: common symptoms for an original diagnosis. Medicine (Baltimore) 2015;94:e2197.

22. Nayak HK, Maurya G, Kapoor N, Kar P. Delayed presentation of congenital diaphragmatic hernia presenting with intrathoracic gastric volvulus: a case report and review. BMJ Case Rep 2012;2012:pii: bcr2012007332.

23. Tarver RD, Conces DJ Jr, Cory DA, Vix VA. Imaging the diaphragm and its disorders. Thorac Imaging 1989; 4:1-18.

24. Kim W, Courtier J, Morin C, et al. Postnatal MRI for $\mathrm{CDH}$ : a pictorial review of late-presenting and recurrent diaphragmatic defects. Diagnosis Clin Imaging 2017; 43:158-64.

25. Praticò FE, Corrado M, Della Casa G, et al. Imaging of congenital pulmonary malformations. Acta Biomed 2016;87:45-50.

26. Zhu Y, Wu Y, Pu Q, et al. Minimally invasive surgery for congenital diaphragmatic hernia: a meta-analysis. Hernia 2016;20:297-302.

27. Kohli N, Mitreski G, Yap CH, Leong M. Massive symptomatic right-sided Bochdalek hernia in an adult man. BMJ Case Rep 2016;2016:pii: bcr2016217432.

28. St Peter SD, Valusek PA, Tsao K, et al. Abdominal complications related to type of repair for congenital diaphragmatic hernia. J Surg Res 2007;140:234-6. 